\title{
Recomendaciones para la analgesia o anestesia de pacientes obstétricas con COVID-19
}

\author{
Alejandro Jankelevich1, Héctor Lacassie Q. ${ }^{2}$, Diana Carolina Carmona ${ }^{3}$, \\ Juan Francisco Morales ${ }^{4}$, Claudio Nazar ${ }^{2}$
}

E siguiente documento es una recomendación de la Sociedad de Anestesiología de Chile en base a la evidencia actual y la opinión de expertos. Como ésta es una situación cambiante, recomendamos mantenerse en constante actualización.

Dada la pandemia por COVID-19 a la que nos estamos viendo enfrentados, se ha considerado la elaboración del siguiente documento que establece directrices en la atención de las pacientes embarazadas con sospecha o confirmación de la infección y que puedan requerir analgesia o anestesia.

\section{Antecedentes}

Hasta ahora no contamos con estadísticas claras respecto a la infección por SARS-CoV-2 en pacientes gestantes, salvo las series de casos en China y Europa de donde se logran extraer algunas conclusiones. Al parecer las embarazadas no son más susceptibles de infectarse por coronavirus, incluso, pareciera afectar más a hombres que mujeres. Sin embargo, se debe considerar la posible presencia de sesgos de reporte, susceptibilidad, exposición, sospecha o diagnóstico. Por los antecedentes que existen del SARS y MERS[1] sabemos que en las embarazadas la infección puede ser desde asintomática hasta causar graves problemas respiratorios y la muerte.

Chen y cols.[2] publicaron una serie de 9 casos de infección por SARS-CoV-2 en mujeres embarazadas en el tercer trimestre. El cuadro clínico que presentaron fue: en 7 casos fiebre, en 4 tos, mialgia en 3, dolor de garganta en 2 y malestar general en 2 casos. En 5 casos se detectó linfopenia y en tres casos elevación de transaminasas. Ninguna paciente desarrolló una neumonía grave por este virus y no hubo muertes.

Zhu y cols.[3] publicaron una serie con 9 embarazadas; los síntomas se iniciaron antes del parto en 4 casos, dos en el mismo día del parto y en el postparto en 3 casos. La clínica fue similar a las no embrazadas, principalmente fiebre y tos. En 6 casos se detectó alteración del bienestar fetal, 7 fueron cesáreas, 6 niños nacieron prematuros y 4 nacieron a término.

El síntoma principal de los recién nacidos fue distrés respiratorio (en 6 casos), dos de ellos tuvieron fiebre, dos presentaron alteración de la función hepática, uno tuvo taquicardia, uno presentó vómitos y otro neumotórax.

La evidencia disponible hasta el momento en cuanto al enfrentamiento de estas pacientes nos dirige a tener un flujo preestablecido que se inicie desde la recepción de la paciente en la urgencia ginecoobstétrica hasta su manejo en puerperio, especificando la instalación de elementos de protección para la paciente y el personal de salud que entre en contacto con ella. Además, una designación de roles que permita optimizar el recurso humano y minimizar la exposición.

Las particularidades a las que nos podemos enfrentar está la superposición de síntomas que alerten al personal de nuestras unidades en la toma de medidas de resguardo, pues en algunas situaciones el cuadro clínico de la infección por SARS-CoV-2 en las mujeres embarazadas puede causar confusión con los síntomas de alguna patología obstétrica como, por ejemplo, sepsis materna por alguna otra causa.

Otras de las dudas se presentan respecto de la probabilidad de transmisión vertical y el manejo a seguir con el recién nacido de una madre con COVID-19. A la fecha no hay evidencia de transmisión vertical en las series revisadas[2],[3], en la cual se realizaron análisis de muestras de líquido amniótico, sangre del cordón umbilical, hisopos de secreción nasal neonatal y de leche materna de pacientes infectadas con SARS-CoV-2, obteniendo resultados negativos en todas.

Hospital Clínico de la Universidad de Chile. Hospital FACH. Santiago, Chile.

División de Anestesiología, Escuela de Medicina, Pontificia Universidad Católica de Chile. Santiago, Chile.

Hospital Luis Tisné. Santiago, Chile.

Clínica Alemana. Santiago, Chile. 
También se desconoce el potencial de transferencia del virus al feto durante el parto vaginal, que ponga en duda la vía de resolución de la gestación. Lo que sí está claro es que en el caso de enfrentarnos a un escenario de sufrimiento fetal causado o asociado a hipoxia por COVID-19, se debe activar el protocolo de cesárea de urgencia o emergencia, según sean las condiciones, lo que conlleva la posibilidad de realizar una anestesia general en una paciente con potencial vía aérea difícil, a lo que se suma el riesgo de transmisión del proceso infeccioso en curso al recién nacido y al personal de salud que la atiende.

Hasta el momento, el enfoque del manejo perianestésico de la paciente embarazada está enfocado en prevenir el contagio del equipo de salud y del resto de los pacientes[4],[5].

\section{Manejo de la paciente en trabajo de parto}

- Cuando una paciente con COVID-19 confirmado o con sospecha es admitida, se debe informar a todos los miembros del equipo multidisciplinario involucrados: médicos obstetra y anestesiólogo, matrona a cargo, equipo auxiliar de quirófano y equipo de neonatología.

- Las mujeres en trabajo de parto que tengan sospecha o confirmación de COVID-19 deben ser atendidas en la sala de partos más cercana disponible al quirófano obstétrico, preferentemente con presión negativa. Si no existe disponibilidad de salas de partos aisladas o no es posible la atención del parto en las salas de parto, se debe considerar realizar el trabajo de parto y atención del parto en un quirófano.

- Las mujeres en trabajo de parto que tengan sospecha o confirmación de COVID-19 deben ser informadas de los posibles retrasos en la atención que pueden ocurrir debido a la necesidad de colocación de elementos de protección personal (EPP).

- Solo se debe permitir un acompañante para el trabajo de parto, preferentemente el padre. El acompañante debe ser tratado como infectado y se le debe pedir que use una mascarilla quirúrgica estándar y se lave las manos frecuentemente. Si está sintomático, el acompañante debe permanecer aislado y no asistir al parto. El acompañante debe mantenerse en la habitación en todo momento.

- Se debe evitar el uso de óxido nitroso para la analgesia de trabajo de parto, dado el riesgo de aerosolización del virus que puede provocarse asociado al sistema de administración de la mezcla de gases.
- La paciente debe usar una mascarilla quirúrgica estándar en todo momento.

- Se debe minimizar la cantidad de personal que transita hacia y fuera de la habitación.

- El personal se debe colocar los EPP en otra habitación y entrar a la habitación con los EPP ya puestos.

- Si es posible, se debe asignar una matrona principal que debe usar EPP apropiados en la habitación y debe mantenerse en ella en todo momento luego de colocarse los EPP.

- Se debe asignar una matrona secundaria que asista a la matrona principal desde afuera de la habitación/quirófano para que la matrona principal no deje su posición.

- Ambas matronas deben intercambiar de rol cada 2 horas.

- Si baja la saturación arterial de oxígeno de la paciente, se debe comenzar la terapia de oxígeno para mantener un valor $>94 \%$. Se debe informar al equipo de la Unidad de Cuidados Intensivos $(\mathrm{UCl})$ y al anestesista si la oxigenación no puede mantenerse por encima de $94 \%$ a pesar de la oxigenoterapia.

- Se recomienda monitorización electrónica fetal continua, especialmente posterior a la anestesia neuroaxial.

\section{Analgesia de trabajo de parto}

- La analgesia epidural y espinal no están contraindicadas en pacientes con COVID-19.

- No se recomienda la realización de exámenes de laboratorio previo a la instalación de la analgesia neuroaxial, a menos que la paciente presente clínica sugerente de alguna alteración que los amerite.

- A las mujeres en trabajo de parto que tengan sospecha o confirmación de COVID-19 se les debe ofrecer una técnica neuroaxial precoz y que se pueda evaluar su efectividad, para reducir el riesgo de anestesia general en caso de emergencia obstétrica.

- Durante la punción neuroaxial se recomienda usar EPP que incluya uso de protección ocular y doble guante, el último de estos deberá ser estéril.

- Siempre que sea posible, se debe asignar al proveedor de anestesia más experimentado para los procedimientos.

- Si se encuentra disponible, se recomienda realizar la mantención de la analgesia de trabajo de parto con métodos automatizados (bombas de infusión 
continua o P(EA) con el fin de disminuir el tránsito del personal anestésico en la habitación de la paciente.

- Cuando la analgesia epidural está contraindicada, se debe ofrecer una PCA de remifentanilo o fentanyl.

\section{Traslado a quirófano}

- En todos los casos que requieran quirófano, todos los miembros del equipo quirúrgico (obstetras, anestesistas, matrón/as, arsenalero/as, auxiliares, neonatólogos) deben usar EPP completo antes de que la paciente sea trasladada.

- La paciente debe ser trasladada por 2 personas "limpias": la matrona secundaria (con EPP limpios) y otro trabajador de la salud. Este equipo debe ser asignado al inicio de cada turno. Se debe despejar los pasillos de personas para evitar contagio.

\section{En el quirófano}

- Se debe elegir un quirófano (idealmente con presión negativa) y una máquina de anestesia exclusiva para las mujeres que tengan sospecha o confirmación de COVID-19, durante toda la duración de la pandemia. Este quirófano debe quedar clausurado y solo en uso para casos de COVID-19. Los EPP deben ser colocados previo al ingreso al quirófano.

- Se debe tener el carro de anestesia fuera de quirófano y solo entrar las drogas e insumos necesarios para cada caso, para ello se recomienda la previa preparación de "kits" con las drogas e insumos a utilizarse ya sea para una anestesia neuroaxial o general.

- Proporcione anestesia epidural o espinal según sea necesario, siempre con los EPP y técnica estéril.

- Evite la anestesia general a menos que sea absolutamente necesario, pero también considérelo dentro de los planes para manejo de técnicas regionales fallidas.

- Si se va a realizar anestesia general, si es posible, todo el personal involucrado en el manejo de la vía aérea debe colocarse una mascarilla N95 y protección ocular. Se debe tener el menor personal posible durante la intubación traqueal, por lo que el personal no involucrado en la intubación debería estar fuera del quirófano
- Se debe realizar preoxigenación con filtro HME en el extremo de la paciente.

- Si es posible, usar apiración con circuito cerrado.

- Se deben realizar todos los esfuerzos para asegurar el éxito en el primer intento de intubación (utilizar videolaringoscopio si está disponible y se tiene experiencia adecuada en su uso, disponer de conductor o bougie, posición en rampa, etc.) y evitar proporcionar ventilación con bolsa-máscara. Para ello es fundamental realizar una preoxigenación adecuada procurando lograr un sello facial con la máscara, sin fugas. Se debe realizar una intubación traqueal de secuencia rápida. Se recomienda sobreponer un plástico transparente sobre la cabeza de la paciente para evitar la aerolización de partículas.

- Para la extubación traqueal, se debe procurar aplicar todas las medidas para minimizar la tos de la paciente, así como la aspiración de secreciones previo a la extubación. Igualmente, se recomienda sobreponer un plástico transparente sobre la cabeza de la paciente para evitar la aerolización de partículas. También se debe minimizar el personal en el quirófano y todo personal directamente involucrado debe estar con mascarilla N95.

- Algunos expertos han sugerido evitar el uso de AINES, sin embargo, esto es controversial y falta evidencia sólida para desestimarlos. Nosotros mantenemos la recomendación de uso de AINES para el manejo de dolor postoperatorio.

- Se deben administrar antieméticos para prevenir los vómitos postoperatorios. Sin embargo, debido a los riesgos potenciales de los esteroides en el contexto de la infección por SARS-CoV-2, considere evitar el uso de dexametasona para la profilaxis de náuseas y vómitos postoperatorios en pacientes con COVID-19 y prefiera otros antieméticos.

- El uso de morfina intratecal no está contraindicado en pacientes con COVID-19 y sugerimos ceñirse a la recomendación de Bauchat y cols.[6], respecto a las dosis a utilizarse y la monitorización requerida.

- Se debe realizar el posoperatorio en el quirófano y, posteriormente, trasladar a su pieza a la paciente y su acompañante con mascarilla quirúrgica, mientras que el personal con los EPP adecuados. La paciente y su acompañante deberán quedar en una pieza con aislamiento de gotitas y contacto. Si la paciente presenta algún signo de gravedad, se debe trasladar a una unidad intermedia. 


\section{Infografías}
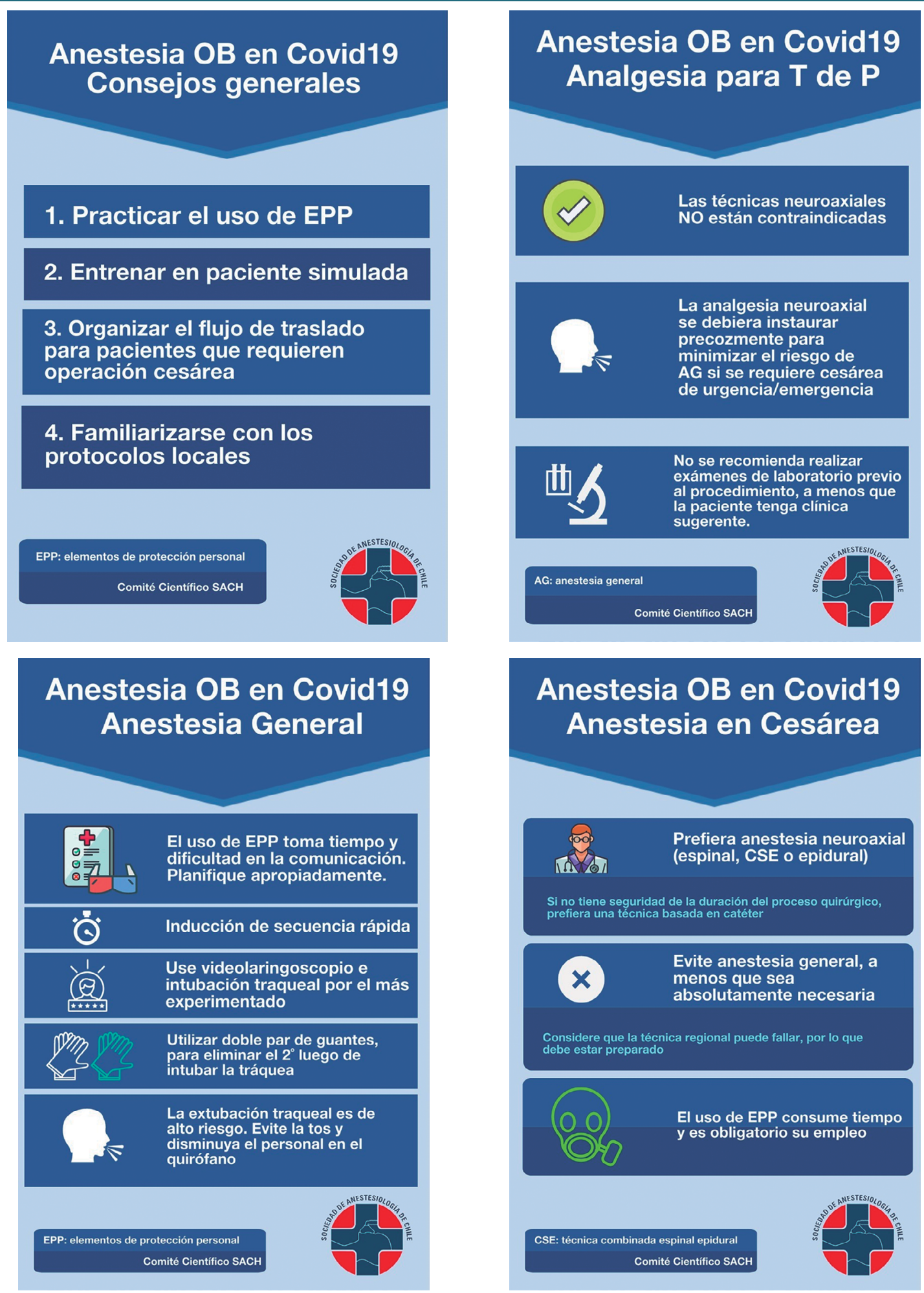


\section{Referencias}

1. Rasmussen SA, Smulian JC, Lednicky JA, Wen TS, Jamieson DJ. Coronavirus Disease 2019 (COVID-19)

and pregnancy: what obstetricians need to know. Am J Obstet Gynecol. 2020 Feb;S0002-9378(20)30197-6. https://doi.org/10.1016/j. ajog.2020.02.017 PMID:32105680

2. Chen H, Guo J, Wang C, Luo F, Yu X, Zhang W, et al. Clinical characteristics and intrauterine vertical transmission potential of COVID-19 infection in nine pregnant women: a retrospective review of medical records. Lancet. 2020 Mar;395(10226):809-15. https://doi.org/10.1016/
S0140-6736(20)30360-3 PMID:32151335

3. Zhu $H$, Wang $L$, Fang $C$, Peng $S$, Zhang L, Chang G, et al. Clinical analysis of 10 neonates born to mothers with 2019-nCoV pneumonia. Transl Pediatr. 2020 Feb;9(1):51-60. https://doi. org/10.21037/tp.2020.02.06 PMID:32154135

4. Chen $R$, Zhang $Y$, Huang $L$, Cheng B, Xia Z, Meng Q. Safety and efficacy of different anesthetic regimens for parturients with COVID-19 undergoing Cesarean delivery: a case series of 17 patients. Canadian Journal of Anesthesia/ Journal canadien d'anesthésie. Springer Science and Business Media LLC; 2020 Mar 16; http:// dx.doi.org/10.1007/s12630-02001630-7
5. Ti LK, Ang LS, Foong TW, Ng BS. What we do when a COVID-19 patient needs an operation: operating room preparation and guidance. Can J Anaesth. 2020 Mar;1-3: https://doi. org/10.1007/s12630-02001617-4 PMID:32144591

6. Bauchat JR, Weiniger CF, Sultan P, Habib AS, Ando K, Kowalczyk JJ, et al. Society for obstetric anesthesia and perinatology consensus statement: monitoring recommendations for prevention and detection of respiratory depression associated with administration of neuraxial morphine for cesarean delivery analgesia. Anesth Analg. 2019 Aug;129(2):458-74. https://doi.org/10.1213/ ANE.0000000000004195 PMID:31082964 